\title{
Epinephrine: Medication Error
}

\author{
Halise Akça', Nilden Tuygun ${ }^{1}$, Emine Polat' ${ }^{2}$, Can Demir Karacan ${ }^{1}$ \\ ${ }^{1}$ Clinic of Pediatric Emergency Medicine, Dr. Sami Ulus Maternity, Children's Health and Diseases Training and Research Hospital, Ankara, Turkey \\ ${ }^{2}$ Clinic of Pediatrics, Dr. Sami Ulus Maternity, Children's Health and Diseases Training And Research Hospital, Ankara, Turkey
}

\begin{abstract}
Epinephrine plays an integral role in the treatment of several life treating diseases. It can be administered at different doses and through different routes of administration. Nebulized L-epinephrine has been described as a safe treatment method. There is a significant difference in doses between nebulization and parenteral administration of epinephrine. Medication errors can result in death due to the use of high-dose epinephrine with parenteral administration. Here we report a child patient who was accidentally exposed to an approximately 30 -fold higher dose of intravenous epinephrine. However, the patient did not develop permanent damage. Medication errors are common in pediatric inpatients, and efforts to reduce them are needed.

(Eurasian J Emerg Med 2016; 15: 111-3)
\end{abstract}

Keywords: Child, epinephrine, medication error

\section{Introduction}

Epinephrine is the main sympathomimetic agent released by the adrenal gland. It plays an integral role in the treatment of several life treating diseases such as cardiac arrest, severe bradycardia, acute hypotension, bronchospasm, and anaphylaxis in the emergency department. It can be administered at different doses and through different routes of administration such as intravenous injection or infusion, umbilical artery or vein injections, endotracheal, intramuscular, local injection or nebulization (1).

A medication error can be defined as a failure in the treatment process that leads to or has the potential to lead to harm a patient. Here we report a child patient who was accidentally exposed to an excessive dose of intravenous epinephrine.

\section{Case Presentation}

An 8-month-old male patient was admitted to the Pediatric Emergency Department of our hospital with fever and respiratory distress because of a possible bronchiolitis. On initial physical examination, his respiratory rate was $60 / \mathrm{min}$ and oxygen saturation was $88 \%$ at room air. He had intercostal retractions and long expiration. Other systemic examinations revealed nothing unusual. His weight was $10 \mathrm{~kg}$. Firstly, he was treated with oxygen, hydration and short acting beta-2 agonist inhalation. On follow up, because the patient did not show gradual recovery, nebulized epinephrine was administered. Nebulized epinephrine treatment was calculated with $5 \mathrm{mg}$ 1:1000 ( $1 \mathrm{mg} / \mathrm{mL})$ epinephrine. The nurse by mistakenly administered epinephrine through the peripheral intravenous route instead by nebulization as ordered. While receiving epinephrine treatment, patient developed paleness, sweating, tremor, and hypotonia. Epinephrine treatment was stopped immediately after $3 \mathrm{mg}(0.3 \mathrm{mg} /$ $\mathrm{kg}$ ) intravenous epinephrine administration. Patient was followed up using a cardiac monitor. A normal sinus rhythm changed to sinus tachycardia at 180-200 beats per minute and urine output decreased (Figure 1). Vital signs were normal except for tachycardia. Symptoms lasted for approximately $2 \mathrm{~h}$ with supported treatment. During follow up, no additional problems were observed. No changes in laboratory test results were observed. The patient needed hospitalization only for acute bronchiolitis. He was followed up for 3 days and discharged without any complication.

\section{Discussion}

Medication errors are the most common type of medical errors to affect children. One of the particularly challenging factors involv-

Correspondence to: Halise Akça e-mail: haliseakca@gmail.com

Received: 05.05.2016 Accepted: 11.05.2016

(C) Copyright 2016 by Emergency Physicians Association of Turkey - Available online at www.eajem.com 


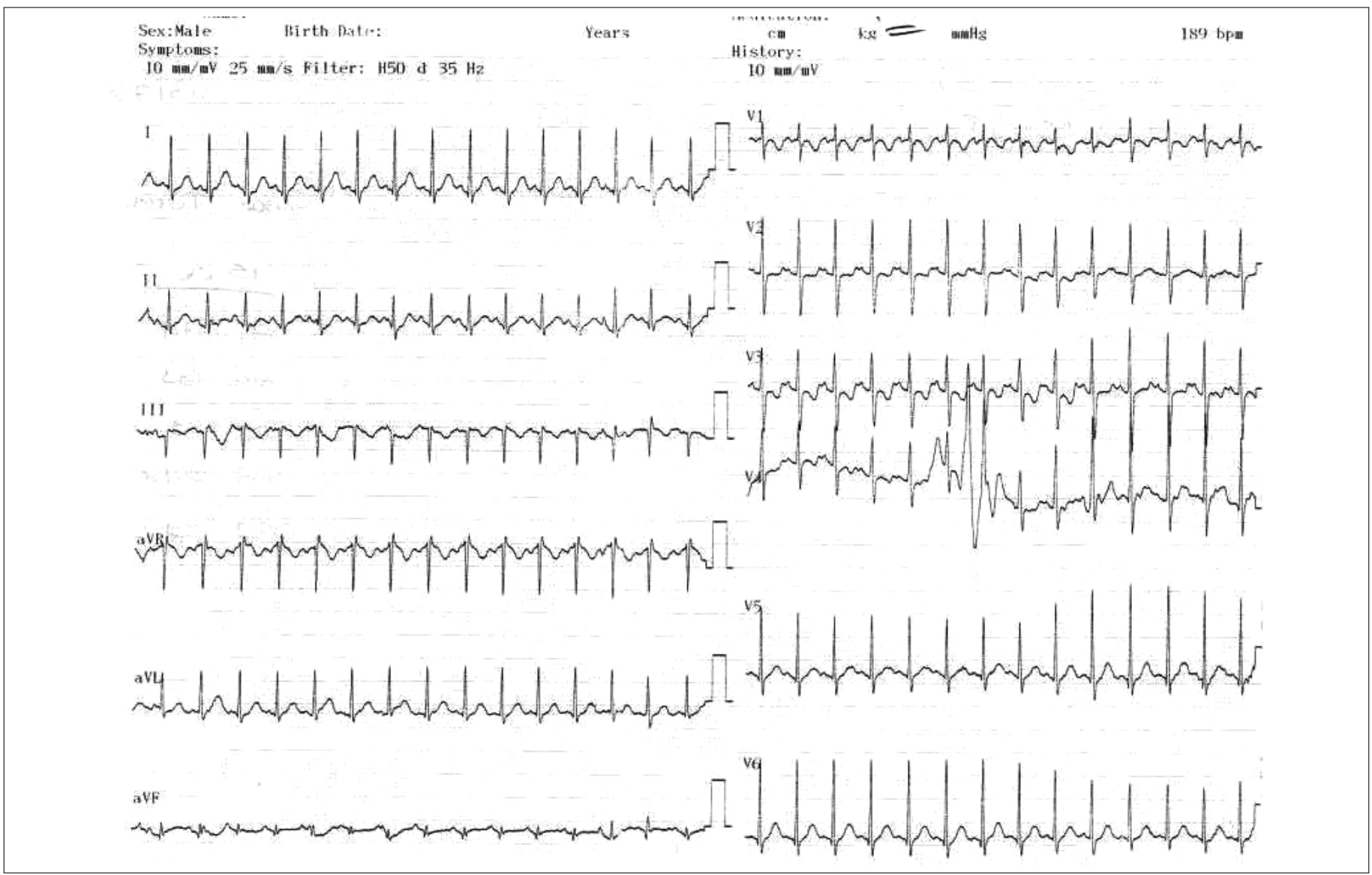

Figure 1. The patient's electrocardiography

ing children is the variation in their size. Errors may occur due to the chaotic and hurried pace in an emergency department (2). Epinephrine remains one of the most important drugs used in emergency care. Although it is used with relative frequency, it continues to be a potential source of harm in many emergency departments (3). Emergency department nurses are at the front line of preventing medication errors in pediatric patients. The academic pediatric community is a critical constituency involved in efforts to improve safe usage and minimize preventable harm from medicines (4).

Epinephrine, with its combined alpha and beta receptor agonist activity, is suggested to be an ideal bronchodilator (5). Nebulized L-epinephrine has been described as a safe treatment method. Patients treated with nebulized epinephrine show only mild side effects such as pallor, debility, tremor, muscle weakness, and early fatigue that regress with supported treatment (6). There is a significant difference in doses between nebulization and parenteral administration of epinephrine. An epinephrine dose of $0.5 \mathrm{mg} / \mathrm{kg}$ is used during nebulization and $0.01 \mathrm{mg} / \mathrm{kg}$ during parenteral administration. The nebulized dose is nearly 50-fold higher than the parenteral dose.

Medication errors can result in death due to the use of high epinephrine doses during parenteral administration. Cohen reported a 7-year-old patient who received a massive overdose of epinephrine (30 mg) intravenously and died the following day (7). A 3-year-old toddler developed multifocal atrial tachycardia following an iatrogenic overdose of epinephrine that was accidentally administered intravenously. His electrocardiogram showed a wandering atrial pacemaker that persisted for at least 1 year (8). In another patient, epinephrine developed severe cardiovascular reactions after $5 \mathrm{mg}$ of intravenous administration. A 12 lead electrocardiogram and neurological examination in the recovery room did not disclose any residual defects (9). Fang et al. reported a 4-day-old newborn who was inadvertently administered a dose of epinephrine that was 100-fold higher than the usual dose; she developed hypokalemia and rhabdomyolysis. No obvious long-term sequelae were observed (10). In our patient, the application of an epinephrine dose was approximately 30 -fold higher than the required dose. Epinephrine plasma half-life was very short (1-2 min). Fortunately, our patient did not develop any permanent damage.

\section{Conclusion}

Epinephrine errors cause by confusion over dose concentrations or routes of administration continue to be a concern in emergency departments. Immediate steps need to be taken to identify the risk and rectify the potential cause of error by providing clear directions to the staff regarding the doses and routes of epinephrine administration. In conclusion, medication errors are common in pediatric inpatients, and efforts to reduce them are required.

Informed Consent: Written informed consent was obtained from the patient's parents.

Peer review: Externally peer-reviewed.

Conflict of Interest: No conflict of interest was declared by the authors. 
Financial Disclosure: The authors declared that this study has received no financial support.

\section{References}

1. Akça $\mathrm{H}$, Tuygun N, Karacan CD. Nebulized Epinephrine Treatment in Pediatric Emergency Medicine. Pediat Therapeut 2014; 4: 210.

2. Cadwell SM. Pediatric medication safety in the emergency department. J Emerg Nurs 2008; 34: 375-7. [CrossRef]

3. Paparella SF. EPINEPHrine: a potpourri of potential medication safety risks. J Emerg Nurs 2013; 39: 151-3. [CrossRef]

4. Shone LP, Yin HS, Wolf MS. Medicine safety among children and adolescents. Acad Pediatr 2010; 10: 218-9. [CrossRef]
5. Simsek-Kiper PO, Kiper N, Hascelik G, Dolgun A, Yalçin E, Doğru Ersöz D, et al. Emergency room management of acute bronchiolitis: a randomized trial of nebulized epinephrine. Turk J Pediatr 2011; 53: 651-60.

6. Zhang L, Sanguebsche LS. The safety of nebulization with 3 to $5 \mathrm{ml}$ of adrenaline (1:1000) in children: an evidence based review. J Pediatr (Rio J) 2005; 81: 193-7. [CrossRef]

7. Cohen M. Epinephrine. Tragic overdose. Nursing 1996; 26: 13.

8. Aburawi $\mathrm{EH}, \mathrm{Narchi} \mathrm{H}$, Souid AK. Persistent wandering atrial pacemaker after epinephrine overdosing - a case report. BMC Pediatr 2013; 13: 1. [CrossRef]

9. Campbell RL. Cardiovascular effects of epinephrine overdose: case report. Anesth Prog 1977; 24: 190-3.

10. Fang W, Chen JY, Fang Y, Huang JL. Epinephrine overdose-associated hypokalemia and rhabdomyolysis in a newborn. Pharmacotherapy 2005; 25: 1266-70. [CrossRef] 